\title{
Sources and Inheritance of Resistance to Fire Blight (Erwinia amylovora) in Eastern U.S. Blackberry Genotypes
}

\author{
Philip J. Stewart ${ }^{1}$ and John R. Clark ${ }^{2}$ \\ Department of Horticulture, University of Arkansas, Fayetteville, AR 72701 \\ Patrick Fenn ${ }^{3}$ \\ Department of Plant Pathology, University of Arkansas, Fayetteville, AR 72701
}

Additional index words. Rubus, small fruit, germplasm, bacterial disease, fruit breeding

\begin{abstract}
Resistance to fire blight in blackberry (Rubus subgenus Rubus Watson) was studied in both seedling populations and clonally propagated plants. Seedling populations resulted from a partial diallel crossing of seven cultivars (Apache, Arapaho, Chester Thornless, Illini Hardy, Navaho, Triple Crown, and Prime-Jim ${ }^{\mathrm{TM}}$ ). Clonal material evaluated included eleven cultivars (Apache, Arapaho, Chester Thornless, Chickasaw, Kiowa, Illini Hardy, Navaho, Ouachita, Shawnee, Triple Crown, and Prime-Jim) and six breeding selections. Inoculations were made by injection of suspensions of Erwinia amylovora in sterile water. Significant differences in resistance were found among genotypes; 'Navaho' was the most susceptible, and 'Kiowa' and a breeding selection A-2095, the most resistant. Seedling inoculations showed resistance to be quantitatively inherited and mostly additive, with an overall narrow-sense heritability of $h^{2}=0.32$.
\end{abstract}

Fire blight, caused by the bacterium Erwinia amylovora (Burr.) Winsl. et al. is a disease that affects many Rosaceous species, with apple (Malus sp.) and pear (Pyrus sp.) being of the greatest economic significance (Bonn and van der Zwet, 2000). Outbreaks are less common in Rubus species, but can reach economically damaging levels under certain conditions (Braun et al., 1999). Incidents have been reported in blackberry in Illinois (Ries and Otterbacher, 1977), Wisconsin (Heimann and Worf, 1985), and recently in eastern Oklahoma (S. von Broembsen, Oklahoma State University, personal communication). The disease has also been a significant problem at times in red raspberries (Rubus idaeus L.) in Canada (Braun et al., 1999; Evans, 1996).

While many evaluations of fire blight resistance in apple and pear genotypes have been conducted, little work has been done with blackberry. Although Ries and Otterbacher (1977) noted several resistant cultivars of red raspberry, their study found all nine blackberry cultivars tested to be very susceptible.

Researchers have investigated the inheritance of resistance to fire blight in apple (Gardner et al., 1980) and pear (Bell et al., 1977), showing it to be primarily additive in nature, but the trait has received little attention in Rubus. Braun et al. (1999) noted that some red raspberry seedlings with the same parents appeared to differ considerably in their level of resistance, and that certain cultivars appeared

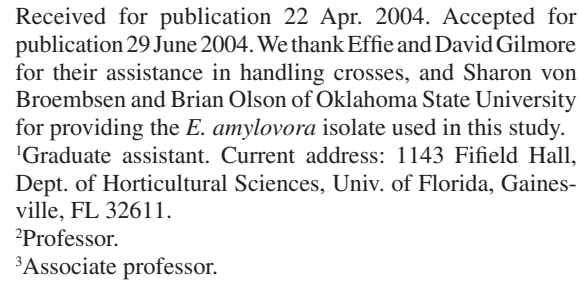

Received for publication 22 Apr. 2004. Accepted for publication 29 June 2004. We thank Effie and David Gilmore for their assistance in handling crosses, and Sharon von Broembsen and Brian Olson of Oklahoma State University for providing the E. amylovora isolate used in this study. ${ }^{1}$ Graduate assistant. Current address: 1143 Fifield Hall, Dept. of Horticultural Sciences, Univ. of Florida, Gainesville, FL 32611.

${ }^{2}$ Professor.

${ }^{3}$ Associate professor.

frequently in the parents of resistant selections. However, no attempt has been made to investigate the inheritance of fire blight resistance in blackberry.

Because of the sporadic nature of fire blight in blackberry, genetic resistance may tive sprays or predictive models. The objective of this study was to determine the level of resistance currently available in a number of eastern U.S. commercial cultivars, and to investigate the inheritance of such resistance in their progeny.

\section{Materials and Methods}

Clonal material. Eleven cultivars and six breeding selections (Table 1) were propagated from dormant root cuttings about $10 \mathrm{~cm}$ long taken from mature plantings at the University of Arkansas Agricultural Research and Extension Center, Fayetteville, and the University of Arkansas Fruit Substation, Clarksville, in December 2002. Twelve to fifteen cuttings of each genotype were potted in Sunshine Mix LC1 (SunGro Horticulture Inc., Bellevue, Wash.) potting mix amended with $50 \mathrm{~mL}$ of Osmocote Vegetable \& Bedding Slow Release Plant Food (The Scotts Company, Marysville, Ohio) fertilizer (14-14-14) per $0.03 \mathrm{~m}^{3}$ of soil in February 2002 and grown in the greenhouse. Five plants of each genotype that served as a parent in crosses were selected for inoculation along with the seedling plants, and six more of each, along with six plants each of 'Kiowa', 'Chickasaw', 'Ouachita', 'Shawnee', 'PrimeJimM', A-2046, A-2095, A-2200, APF-19, APF-37, and APF-41, were selected for use in the clonal study. An additional two plants each of 'Arapaho', 'Apache', and 'Navaho' were also selected as controls. All plants were transplanted into 10.2-cm pots in late April. Each be a better option for control than preventa- plant had a single primocane that was about 30 $\mathrm{cm}$ in length at the time of inoculation.

Seedling populations. Seedling populations were obtained from crosses made in April and May 2002 (Table 2). The parents were selected to provide a wide range of genetic backgrounds among eastern-U.S. cultivars in the hopes that some would differ in level of resistance to fire blight. Parents were 'Apache' (Clark and Moore, 1999), 'Arapaho' (Moore and Clark, 1993), 'Navaho' (Moore and Clark, 1989), and 'Prime-Jim' (John R. Clark, personal communication) from the University of Arkansas breeding program, 'Triple Crown' (Moore, 1997), and 'Chester Thornless' (Moore, 1997) from the U.S. Dept. of Agriculture breeding program, and 'Illini Hardy' (Moore, 1997), released by the University of Illinois. Several reciprocal crosses were made in order to detect maternal effects. Crosses were made on 'Apache' and 'Arapaho' at the University of Arkansas Agricultural Research and Extension Center, Fayetteville, and on Prime-Jim, 'Illini Hardy', 'Navaho', 'Triple Crown', and 'Chester Thornless' at the University of Arkansas Fruit Substation, Clarksville. Flowers were emasculated by hand, bagged in plastic mesh bags to exclude foreign pollen and insects, and pollinated 1 or $2 \mathrm{~d}$ later depending on weather and visible pistil receptiveness. Anthers were extracted from these same plants, allowed to dry for several days, and stored with resulting pollen in glass bottles in a refrigerator at $5^{\circ} \mathrm{C}$.

Seeds were extracted from mature fruit and air-dried. Scarification of dry seeds was in $95 \%$ sulfuric acid for $3 \mathrm{~h}$ (Moore et al., 1974). Seeds were then stratified in moist potting soil for 17 weeks at $5{ }^{\circ} \mathrm{C}$. They were sown in the greenhouse in December 2002, and transplanted at the cotyledon stage of growth into $7.6-\mathrm{cm}$ pots of Sunshine Mix LC1 potting soil amended with $50 \mathrm{~mL}$ of Osmocote Vegetable \& Bedding Slow Release Plant Food fertilizer (14-14-14) per $0.03 \mathrm{~m}^{3}$ of soil. If a population had more than 30 seedlings, only the first 30 were transplanted for use in the study. Most plants had one or two primocanes, and were generally about 30 $\mathrm{cm}$ in length. All plants were watered twice daily, as needed, until inoculation.

Inoculum. A culture of E. amylovora isolated from blackberries in eastern Oklahoma was obtained from S. von Broembsen and B. Olson at Oklahoma State University in 2002. It was verified as E. amylovora by streaking on Crosse and Goodman media (Crosse and Goodman, 1973), where it displayed typical colony morphology. The bacterium was grown in a liquid culture of 523 medium (Kado and Heskett, 1970), and stored at $-20{ }^{\circ} \mathrm{C}$ in solution with $15 \%$ glycerol. Two d before inoculations, frozen stock was streaked on plates of 523 medium and incubated at $28{ }^{\circ} \mathrm{C}$. Using a bacteria transfer loop, two loopfuls of bacteria were taken from the plate and mixed vigorously with $10 \mathrm{ml}$ of sterile distilled water to provide a uniform suspension of about $1 \times 10^{8}$ colony forming units per $\mathrm{ml}$.

Inoculation. Plants were inoculated by inserting a No. 30 hypodermic needle completely through the stem just below the first fully unfolded leaf. Sufficient liquid was ejected to 
completely fill the wound and leave a droplet on either side (Norelli et al., 1988). Controls were treated similarly with sterile water.

To enhance disease development, the greenhouse was maintained at $24{ }^{\circ} \mathrm{C}$ day/22 ${ }^{\circ} \mathrm{C}$ night, and kept shaded using shade cloth. Also, inoculated plants were misted with water twice daily at $9 \mathrm{AM}$ and $4 \mathrm{PM}$ to maintain humidity and watered at $12 \mathrm{PM}$. All seedlings received an additional misting immediately following inoculation.

At 5 and $10 \mathrm{~d}$ after inoculation, plants were rated for symptom development on a scale of 0 to 5 , as follows: $0=$ no symptoms; $1=$ water-soaking only; 2 = localized discoloration, no more than $3 \mathrm{~cm}$ in length; $3=$ significant discoloration, more than $3 \mathrm{~cm}$ in length; infection apparent in leaves or petioles; $4=$ extensive discoloration, ooze produced, leaves begin to wilt; $5=$ plant above inoculation point completely necrotic, extensive discoloration and ooze production. Five days after ratings were taken, 10 severely diseased and 10 symptomless plants were randomly selected and sampled at the point of inoculation. The samples were surface disinfested by immersion in $1.5 \%$ sodium hypochlorite for $5 \mathrm{~min}$, cut into small segments, and soaked overnight in distilled water. The liquid was then streaked on Crosse and Goodman Erwinia selective media to check if the bacteria persisted in the tissue. E. amylovora was identified by colony morphology.

Seedlings were arranged in the greenhouse in five replications, each containing one to six plants of each population, in a randomized complete block design. Additionally, one plant each of the seven parental genotypes was included in each replication. Replications 1 and 2 also included an additional plant each of 'Arapaho', 'Apache', and 'Navaho', which were injected with sterile water as controls. Replication 1 was inoculated as described above on 5 May 2003, followed by replication 2 on 7 May, replication 3 on 9 May, and replications 4 and 5 on 11 May 2003.

A separate study of clonal material began 1 June 2003, using six plants of each of the 17 genotypes tested. Plants were arranged in a randomized complete block design with a single plant of each genotype in each replication. The five plants of each clonal genotype used as a parent and included in the seedling study were also included in the final analysis of this study as a separate trial. Inoculation procedures and environmental conditions were identical to those used in the seedling study.

Data analysis. Data from the clonal study were analyzed by analysis of variance with the JMP 5.0 statistical software package (SAS Institute Inc., Cary, N.C.). Analysis of variance was used to determine the effect of replication and trial on severity ratings. Average ratings for each clonal genotype were computed and compared using Duncan's multiple range test.

Because chi-square analysis of the seedling data did not suggest a qualitatively inherited trait, the inheritance was treated as quantitative. Narrow-sense heritability for the seedling group as a whole was computed by offspringmidparent regression analysis. General and specific combining ability (GCA and SCA) were also computed, with SAS Statistical Software, version 8.0 (SAS Institute Inc., Cary, N.C.)

\section{Results}

Clonal material study. Genotype was the main source of variance in this study. Differences between the ratings of parental genotypes inoculated in the seedling study and those in the subsequent clonal study were found to be statistically insignificant, so data from those two trials were merged. A wide range of resistance to fire blight was found among the genotypes evaluated (Table 1). Of the 17 genotypes, seven had average ratings of $<1.0$. These included the cultivars Triple Crown, Arapaho, Kiowa, and Prime-Jim and three breeding selections, APF-41, A-2200, and A-2095. 'Navaho' was

Table 1 . Average disease severity rating $\left(0\right.$ to $\left.5^{z}\right)$ of blackberry genotypes $10 \mathrm{~d}$ after inoculation with Erwinia amylovora.

\begin{tabular}{|c|c|c|c|}
\hline Genotype & Parentage & Mean rating & $\mathrm{n}$ \\
\hline Navaho & $(\mathrm{A}-583 \times \mathrm{A}-631)$ & $3.9 \mathrm{a}^{\mathrm{y}}$ & 11 \\
\hline Apache & (A-1007 $\times$ Navaho) & $2.6 \mathrm{~b}$ & 11 \\
\hline $\mathrm{APF}-37^{\mathrm{x}}$ & $(\mathrm{APF}-12 \times \mathrm{APF}-8)$ & $2.5 \mathrm{bc}$ & 6 \\
\hline Ouachita & (Navaho × A-1506) & $2.0 \mathrm{bcd}$ & 6 \\
\hline Shawnee & $($ Cherokee $\times$ A-586) & 1.8 bcde & 6 \\
\hline Chickasaw & $(\mathrm{A}-842 \times \mathrm{A}-1246)$ & 1.5 bcde & 6 \\
\hline Illini Hardy & (NY $95 \times$ Chester Thornless) & 1.4 cde & 11 \\
\hline APF-19 & $(\mathrm{APF}-1 \times \mathrm{APF}-12)$ & $1.2 \mathrm{cde}$ & 6 \\
\hline Chester Thornless & (Thornfree $\times$ Darrow) & $1.1 \mathrm{de}$ & 11 \\
\hline A-2046 & $(\mathrm{A}-1539 \times \mathrm{A}-1545)$ & $1.0 \mathrm{cde}$ & 6 \\
\hline Triple Crown & (SIUS 68-2-5 × A-945) & $0.9 \mathrm{de}$ & 11 \\
\hline Arapaho & $(\mathrm{A}-631 \times \mathrm{A}-883)$ & $0.8 \mathrm{e}$ & 11 \\
\hline Prime-Jim ${ }^{\mathrm{TM}}$ & $($ Arapaho $\times$ A-830) & $0.8 \mathrm{e}$ & 11 \\
\hline APF-41 & (APF-1 × APF-12) & 0.6 cde & 6 \\
\hline A-2200 & $(\mathrm{A}-1845 \times \mathrm{A}-1792)$ & 0.6 cde & 6 \\
\hline A-2095 & $(\mathrm{A}-1629 \times \mathrm{A}-1758)$ & $0.1 \mathrm{de}$ & 6 \\
\hline Kiowa & $(\mathrm{A}-791 \times \mathrm{A}-1058)$ & $0.1 \mathrm{de}$ & 6 \\
\hline
\end{tabular}

${ }^{2}$ Ratings scale: $0=$ no symptoms, $5=$ severe necrosis

${ }^{y}$ Mean separation: means followed by the same letter do not differ significantly $(P \leq 0.05)$ according to Duncan's multiple range test.

${ }^{x}$ APF-19, APF-37, APF-41, A-2046, A-2095, and A-2200 are breeding selections and not currently available in commerce.

Table 2. Disease severity ratings of blackberry seedling populations $10 \mathrm{~d}$ after inoculation with Erwinia amylovora.

\begin{tabular}{|c|c|c|c|c|c|c|c|c|}
\hline \multirow[b]{2}{*}{ Parentage } & \multicolumn{6}{|c|}{$\begin{array}{c}\text { Distribution by } \\
\text { seedling severity rating }\end{array}$} & \multirow[b]{2}{*}{$\mathrm{n}$} & \multirow{2}{*}{$\begin{array}{l}\text { Mean } \\
\text { rating }\end{array}$} \\
\hline & 0 & 1 & 2 & 3 & 4 & 5 & & \\
\hline Apache $\times$ Arapaho & 0 & 0 & 1 & 2 & 1 & 0 & 4 & 3.0 \\
\hline Apache $\times$ Illini Hardy & 0 & 0 & 2 & 0 & 1 & 0 & 3 & 2.7 \\
\hline Apache $\times$ Triple Crown & 3 & 2 & 1 & 3 & 2 & 2 & 13 & 2.4 \\
\hline Arapaho $\times$ Apache & 8 & 2 & 1 & 0 & 0 & 1 & 12 & 0.7 \\
\hline Arapaho $\times$ Navaho & 8 & 3 & 7 & 2 & 6 & 4 & 30 & 2.2 \\
\hline Arapaho $\times$ Illini Hardy & 1 & 0 & 1 & 1 & 0 & 1 & 4 & 2.5 \\
\hline Prime-Jim ${ }^{\mathrm{TM}} \times$ Arapaho & 6 & 2 & 6 & 2 & 1 & 0 & 17 & 1.4 \\
\hline Chester Thornless $\times$ Arapaho & 2 & 1 & 0 & 0 & 0 & 0 & 3 & 0.3 \\
\hline Chester Thornless $\times$ Illini Hardy & 4 & 0 & 2 & 1 & 2 & 0 & 9 & 1.7 \\
\hline Navaho $\times$ Apache & 4 & 5 & 7 & 8 & 6 & 0 & 30 & 2.2 \\
\hline Navaho $\times$ Arapaho & 8 & 6 & 5 & 5 & 3 & 3 & 30 & 1.9 \\
\hline Navaho $\times$ Prime-Jim & 3 & 1 & 2 & 0 & 2 & 2 & 10 & 2.3 \\
\hline Navaho $\times$ Chester Thornless & 6 & 6 & 7 & 5 & 6 & 0 & 30 & 2.0 \\
\hline Navaho $\times$ Illini Hardy & 3 & 5 & 2 & 4 & 7 & 7 & 28 & 3.0 \\
\hline Navaho $\times$ Triple Crown & 7 & 3 & 9 & 5 & 4 & 2 & 30 & 2.1 \\
\hline Illini Hardy $\times$ Prime-Jim & 0 & 0 & 0 & 0 & 1 & 0 & 1 & 4.0 \\
\hline Illini Hardy $\times$ Arapaho & 1 & 0 & 1 & 3 & 0 & 1 & 6 & 2.7 \\
\hline Illini Hardy $\times$ Navaho & 0 & 1 & 0 & 0 & 0 & 1 & 2 & 3.0 \\
\hline Illini Hardy $\times$ Triple Crown & 1 & 1 & 1 & 2 & 3 & 1 & 9 & 2.9 \\
\hline Triple Crown $\times$ Apache & 4 & 5 & 6 & 6 & 7 & 1 & 29 & 2.3 \\
\hline Triple Crown $\times$ Arapaho & 4 & 4 & 4 & 0 & 1 & 1 & 14 & 1.5 \\
\hline Triple Crown $\times$ Illini Hardy & 10 & 5 & 5 & 4 & 5 & 1 & 30 & 1.7 \\
\hline
\end{tabular}


Table 3. General combining ability (GCA) estimates for resistance to Erwinia amylovora in blackberry crosses. Data from reciprocal crosses was pooled.

\begin{tabular}{lrcc}
\hline Genotype & GCA & SE & $P$ \\
\hline Apache & 0.19 & 0.179 & 0.285 \\
Arapaho & -0.36 & 0.174 & 0.039 \\
Chester Thornless & -0.52 & 0.239 & 0.029 \\
Illini Hardy & 0.45 & 0.183 & 0.015 \\
Navaho & 0.42 & 0.166 & 0.012 \\
Triple Crown & -0.12 & 0.176 & 0.489 \\
Prime-Jim $^{\mathrm{TM}}$ & -0.06 & 0.282 & 0.845 \\
\hline
\end{tabular}

data analysis and reporting. No control plants treated with sterile water showed symptoms at either 5 or $10 \mathrm{~d}$.

Seedling populations expressed a wide range of reactions to inoculations with $E$. amylovora (Table 2). Six populations had a mean severity rating of $<2.0$, although each contained a full range of individual ratings. Of these, 'Triple Crown' $\times$ 'Illini Hardy' contained the greatest number of individuals that showed no symptoms, fully a third of the population. Except for 'Navaho' $\times$ 'Chester Thornless', each of these populations had either 'Triple Crown', or 'Arapaho' as a parent. The most susceptible population was from the cross 'Navaho' $x$ 'Illini Hardy'.

Offspring-midparent regression generated a narrow-sense heritability estimate of $h^{2}=0.32$ for the population. No significant SCA effects were seen for any combination of parental genotypes. General combining ability estimates were significant for a number of genotypes, and ranged from -0.53 for 'Chester Thornless', to 0.45 for 'Illini Hardy' (Tables 3 and 4). The amount of variation due to GCA was over four times that of SCA (Table 4).

E. amylovora bacteria were recovered $17 \mathrm{~d}$ after inoculation from 8 of 10 severely affected (rating $=5$ ) seedlings and 3 of 10 seedlings with no symptoms (rating $=0$ ). This confirmed the presence of the bacterium in the seedling plants.

\section{Discussion}

Genetic differences in susceptibility to infection by $E$. amylovora were present in the blackberry genotypes studied. This was expected, as such differences have been observed in many of E. amylovora's host species, including the closely related red raspberry (Braun et al., 1999; Ries and Otterbacher, 1977). However, the present results appear to be the first observation of resistance to fire blight in blackberry. Hall (1990) noted no resistance in his review of blackberry breeding, and Ries and Otterbacher (1977) found little difference in susceptibility among blackberry genotypes in their inoculation study of both thorny and thornless blackberry cultivars. This may have been a coincidence of the genotypes included in their study, or it may be a result of their reliance on frequency of symptoms, rather than severity, as a measure of cultivar susceptibility.

While inoculation studies cannot precisely measure field performance, they can still reveal important genetic differences in resistance. By averaging in ratings of 0 for unaffected plants with ratings of symptomatic plants, the average rating in this study was similar to the index of susceptibility proposed by Thibault et al. (1987), because it accounts for both frequency of infection and the severity of those infections which do occur.

In general, resistance to E. amylovora appeared to be moderately heritable, and most of the genetic variance was found to be additive. Rather than falling into distinct classes, seedling ratings showed a wide range of variation typical for a quantitatively inherited trait. The lack of significance in estimates of SCA effects, and the small proportion relative to the GCA, indicated that for the parents used in this study, dominant gene action seems to play a fairly limited role in determining the level of resistance to fire blight. While the size of the populations and the reliance on a single year of data necessarily limit the conclusions that can be drawn from the data, the fact that only a few populations display the sort of normal distribution that might be expected for a purely additive, quantitative, trait may however indicate that at least a few minor dominant alleles have affected the distribution in some cases.

Of the six cases in which populations with reciprocal crosses existed, only two showed significant differences between reciprocals, 'Apache' $\times$ 'Arapaho' and 'Illini Hardy' $\times$ 'Triple Crown'. Because these two instances both involved small populations, and because no reciprocal differences appeared in other crosses with the same cultivars, it was concluded that maternal effects were insignificant in determining genetic resistance.

'Navaho' was the most susceptible of the cultivars, and also a parent of two other susceptible cultivars, 'Apache' and 'Ouachita'. In the seedling study, 'Navaho' imparted this susceptibility to its progeny, with a GCA of 0.42 . The only parent contributing more to susceptibility was 'Illini Hardy', with a GCA of 0.45 , which was not itself rated among the most susceptible cultivars. In the pair of reciprocal crosses between these two cultivars half of the progeny were rated 4 or 5 .

The two parents with the most negative GCA estimates were 'Arapaho' and 'Chester Thornless'. Nearly half of the 'Arapaho' plants displayed no symptoms, and no plant was rated $>2$. Although a few individuals of 'Chester Thornless' displayed more severe symptoms, the mean values for these two cultivars did not differ significantly. Two other cultivars with similar ratings in the clonal study, 'Triple Crown' and 'Prime-Jim', had statistically insignificant impacts on the susceptibility of their progeny, with GCA estimates for susceptibility of -0.12 and -0.05 , respectively.

Although the involvement of a single major gene for resistance or susceptibility was not identified, it is possible that such genes do exist.
Because the blackberries used in this study are all tetraploid, relatively large numbers would be needed to reveal the segregation ratios predicted by Mendelian inheritance, and the populations used in this study were too small to allow effective study of many such ratios. It is also possible that while major dominant alleles may play a role in some genotypes, none occurred in the genotypes selected as parents in this study. Resistance in apples and pears, while primarily additive, can involve major gene effects in some cases, notably the $S e$ gene for fire blight sensitivity in pear (Thompson et al., 1975), and a dominant resistance gene in apples derived from the rootstock 'Robusta 5' (Gardner et al., 1980). Luby et al. (2002) suggest that an accession of $M$. honanesis Rehder in their study may contain the apple equivalent of the $S e$ gene in pear. Because both blackberries and E. amylovora are native to North America, the opportunity may have existed for a broad base of genetic resistance to develop.

The narrow-sense heritability estimate of $h^{2}=0.32$ is roughly in line with those calculated for apple and pear by previous researchers. In a study of a diverse collection of apple germplasm in New Zealand, Luby et al. (2002) found $h^{2}$ values for most sublines to be in the range of 0.12 to 0.36 . Bell et al. (1977) calculated an estimate of $h^{2}=0.46$ for crosses of $P$. communis L. parents lacking the $\mathrm{Se}$ allele for sensitivity.

Based on these results, it should be possible for a breeder to make progress in improving the resistance level by selecting parents based on phenotype. In this method, parental genotypes with high levels of resistance are intercrossed, and resistant seedlings identified among the resulting progeny. Such a breeding strategy has been effective in breeding for fire blight resistance in both apples and pears, while simultaneously selecting for desirable horticultural characteristics (Cameron et al., 1969; Gardner et al., 1980). However, because roughly two-thirds of the variance appears to be environmental, not genetic, multiple sites and seasons may be necessary to accurately gauge the level of resistance present in a given plant.

The recovery of E. amylovora from asymptomatic tissues is evidence that the lack of symptoms was not a result of a failure of the inoculation technique, but an inability of the bacterium to cause disease in the plant. It is possible, however, that the presence of bacteria in samples from symptomless plants could be due to contamination.

Fire blight in Rubus species is not well understood, and much research remains to be done. The role, if any, that differential virulence among E. amylovora strains plays in the reaction of blackberries and the degree of cultivar specificity remain unknown, as does almost the

Table 4. Mean square, F ratio, and $P$ value for general (GCA) and specific (SCA) combining ability for resistance to Erwinia amylovora.

\begin{tabular}{lrccc}
\hline Source & df & Mean square & F ratio & $P$ \\
\hline GCA & 6 & 7.302 & 2.92 & 0.01 \\
SCA & 15 & 1.771 & 0.69 & 0.71 \\
Error & 337 & 873.626 & & \\
\hline
\end{tabular}


entire epidemiology of the disease in Rubus. The susceptibility of 'Boyne' red raspberry to apple isolates of the bacteria, observed by Evans (1996), and the close genetic similarity of some Rubus isolates to those from apple and pear (Kim et al., 1996), suggests that it may be important to determine whether Rubus bacterial strains are as host-specific as previously thought, and if plantings of apple, pear, and other host species pose a risk as inoculum sources for blackberries and raspberries. To successfully breed resistant cultivars of blackberries, more extensive surveys of existing cultivars, breeding materials, and perhaps wild species are needed to better identify sources of resistance.

\section{Literature Cited}

Bell, R.L., J. Janick, R.H. Zimmerman, and T. van der Zwet. 1977. Estimation of heritability and combining ability for fire blight resistance in pear. J. Amer. Soc. Hort. Sci. 102:133-138.

Bonn, W.G. and T. van der Zwet. 2000. Distribution and economic importance of fire blight, p. 37-53. In: J.L. Vanneste (ed.). Fire blight: The disease and its causative agent, Erwinia amylovora. CABI Publ., Cambridge, Mass.

Braun, P.G., P.D. Hildebrand, and A.R. Jamieson. 1999. Screening raspberries for resistance to fire blight (Erwinia amylovora). Acta Hort. 505:369-372.

Cameron, H.R., M.N. Westwood, and P.B. Lombard. 1969. Resistance of Pyrus species and cultivars to Erwinia amylovora. Phytopathology 59:1813-1815.

Clark, J.R. and J.N. Moore. 1999. 'Apache' thornless blackberry. HortScience 34:1291-1293.

Crosse, S.E. and R.N. Goodman. 1973. A selective medium for a definitive colony characteristic of Erwinia amylovora. Phytopathology 63:1425-1426.

Evans, I.R. 1996. Fire blight of raspberries in Alberta. Acta Hort. 411:69-72

Gardner, R.G., J.N.Cummins, and H.S. Aldwinckle. 1980. Inheritance of fire blight resistance in Malus in relation to rootstock breeding. J. Amer. Hort. Soc. Sci. 105:912-916.

Hall, H. 1990. Blackberry breeding, p. 249-312. In: J. Janick (ed.). Plant breeding reviews. vol. 8 . Wiley, New York.

Heimann, M.F. and G. L. Worf. 1985. Fire blight of raspberry caused by Erwinia amylovora. Plant Dis. 69:360 (abstr.).

Kado, C.I. and M.G. Heskett. 1970. Selective media for isolation of Agrobacterium, Corynebacterium, Pseudomonas, and Xanthomonas. Phytopathology 60:969-976.

Kim, J.-H., S.V. Beer, A. Tanii, C.H. Zumoff, R.J. Laby, H.L. Gustafson, and H.S. Aldwinckle, 1996. Characterization of Erwinia amylovora strains from different hosts and geographical areas. Acta Hort. 411:183-186.

Luby, J.J., P.A. Alspach, V.G.M. Bus, and N.C. Oraguzie. 2002. Field resistance to fire blight in a diverse apple (Malus sp.) germplasm collection. J. Amer. Soc. Hort. Sci. 127:245-253.

Moore, J.N. 1997. Blackberries, p.161-173. Brooks and Olmo register of fruit and nut varieties. 3rd ed. ASHS Press, Alex., Va.

Moore, J.N., G.R. Brown, and C. Lundergan. 1974. Effect of duration of acid scarification on endocarp thickness and seedling emergence of blackberries. HortScience 9:204-205.

Moore, J.N. and J.R. Clark, 1993. 'Arapaho' erect thornless blackberry. HortScience 28:861-862.

Moore, J.N. and J.R. Clark. 1989. 'Navaho' thornless blackberry. HortScience 24:863-865.

Norelli, J.L., H.S. Aldwinckle, and S.V. Beer. 1988. Virulence of Erwinia amylovora strains to Malus sp. Novole plants grown in vitro and in the greenhouse. Phytopathology 78:1292-1297.

Ries, S.M. and A.G. Otterbacher. 1977. Occurrence of fire blight on thornless blackberry in Illinois. Plant Dis. Rptr. 61:232-235.

Thibault, B., P.LeComte, L. Herman, and A. Belouin. 1987. Comparison between two methods of selection for resistance to E. amylovora in young seedlings in pear. Acta Hort. 217:265-272.

Thompson, J.M., R.H. Zimmerman, and T. van der Zwet. 1975. Inheritance of fire blight resistance in Pyrus. I. A dominant gene $S e$, causing sensitivity. J. Hered. 66:259-264. 